\title{
Effects of Short-Term Intravenous Administration of Diltiazem on Left Ventricular Function and Coronary Hemodynamics in Patients with Coronary Artery Disease
}

\author{
P. W. Serruys, H. Suryapranata, J. Planellas, W. Wijns, G. Vanhaleweyk, B. E. Jaski, \\ and P. G. Hugenholtz
}

Thoraxcenter, Erasmus University, Rotterdam, The Netherlands

\begin{abstract}
Summary: The hemodynamic effects of diltiazem were investigated in 15 patients with suspected coronary artery disease undergoing routine cardiac catheterization. Diltiazem was given in a high dose of $500 \mu \mathrm{g} / \mathrm{kg}$ over a period of $5 \mathrm{~min}$ and measurements made before and after drug administration during spontaneous heart rate and during matched atrial pacing. Spontaneous heart rate did not change $(-5 \%$; NS). Left ventricular (LV) systolic pressure decreased $24 \%\left(\mathrm{p}<10^{-6}\right)$ and LV end-diastolic pressure (LVEDP) did not change ( $-5 \%$; NS). During coronary blood flow measurement, mean aortic pressure decreased $30 \%\left(\mathrm{p}<10^{-6}\right)$ as global (coronary sinus) and regional (great cardiac vein) coronary vascular resistance diminished with no change in coronary blood flow. Myocardial oxygen consumption decreased $19 \%$ ( $p<0.02$ ).
\end{abstract}

During matched pacing, although no change occurred in calculated systolic isovolumic indexes of contractility, end-systolic pressure-volume index decreased $15 \%$ ( $\mathrm{p}<$ 0.05 ). The time constant of isovolumic relaxation assessed by a biexponential model decreased. No net change occurred in either global or regional wall motion. In summary, high-dose diltiazem was administrated safely to patients with coronary artery disease. It is concluded that, at this dose, diltiazem acted as a peripheral and coronary vasodilator. Hemodynamic changes consistent with a direct negative inotropic and chronotropic effect of the drug were observed. Myocardial oxygen consumption decreased with no change in coronary blood flow. Key Words: Calcium antagonist-Diltiazem-Hemodynamic effects - Coronary artery disease.
Calcium antagonists represent an important new class of antianginal, antiarrhythmic, and, probably, antihypertensive drugs.

Diltiazem, a benzothiazepine derivative (1) and one of the calcium slow channel blocking agents, has been studied in vitro (2), but little information exists concerning its application in humans. In experimental animals, the drug exerts a powerful systemic and coronary vasodilator action and slight negative inotropic and chronotropic effects $(2,3)$. Clinical studies with oral administration or intravenous infusion in humans have demonstrated that diltiazem has a beneficial antianginal effect in effort angina and angina at rest. Controversy exists, however, over the net myocardial and coronary vascular effects of diltiazem, since direct actions can be offset by reflex changes (3-7).

Investigators have studied the effects of low or moderate doses of diltiazem $(3-8)$. Therefore, the present study investigated the effects of a single high dose of intravenous diltiazem in humans $(500$ $\mu \mathrm{g} / \mathrm{kg}$ over $5 \mathrm{~min}$ ). Before and after diltiazem administration, two approaches were used to elucidate the net effects of the drug. First, left ventricular (LV) function, myocardial oxygen consumption, and coronary hemodynamics were assessed at spontaneous heart rate. Second, LV function and global and regional wall motion were assessed by pressure measurements and LV angiography at a constant, paced heart rate.

\section{METHODS AND PATIENTS}

Fifteen patients undergoing investigation for chest pain were studied at the time of cardiac catheterization. All patients were men. The mean age was 60 years (range, $53-68$ years). 
Coronary artery disease was defined as a $70 \%$ diameter reduction of one or more major coronary arteries. One patient with atypical chest pain proved to have normal coronary arteries. Seven patients had previous myocardial infarction. None had clinical signs of congestive heart failure. In all patients, informed consent to participate in the study was obtained. Patient data are summarized in Table 1 (9).

\section{Protocol}

$\beta$-Blockers, nitrates, calcium antagonists, and digitalis were discontinued $36 \mathrm{~h}$ before the study. The cardiac catheterization was performed with patients in the fasting state without premedication.

A Baim [coronary sinus (CS) and great cardiac vein (GCV)] (10) flow catheter or a Ganz CS flow thermodilution catheter was inserted into the CS from a right antecubital vein. A micromanometer-tipped 8 French pigtail catheter (Millar Instruments, Texas, U.S.A.) was advanced into the left ventricle.

The following measurements were made: heart rate, aortic and LV pressures, pressure-derived indices of isovolumic contraction and relaxation (see below), thermodilution CS and GCV flow, and oxygen saturation obtained simultaneously from the aorta and CS.

To assess hemodynamic changes independent of changes in heart rate, measurements were made during spontaneous heart rate and at a matched atrial paced heart rate before and after diltiazem administration. After establishing control state at least $10 \mathrm{~min}$ following catheter instrumentation, measurements were made according to the following protocol:

(a) In a control state, during LV cineangiography, at a paced heart rate 15 beats above spontaneous heart rate. LV cineangiogram was performed at 50 frames/s, obtained in a $30^{\circ}$ right anterior oblique position by injection of a nonionic contrast medium (Omnipaque). Stroke volume was computed as the difference in computed volume between end-diastolic and end-systolic volumes Movement of the diaphragm was excluded by instructing the patient to take a shallow inspiration, taking care to avoid a Valsalva maneuver.

(b) In a control state, without angiography, at the same paced heart rate during recording of LV pressures.

(c) In a control state, at a spontaneous heart rate, during measurement of coronary blood flow and recording of LV and aortic pressures.

(d) Two minutes following a 5-min infusion of diltiazem at a rate of $100 \mu \mathrm{g} / \mathrm{kg} / \mathrm{min}$ at a spontaneous heart rate during measurement of coronary blood flow and recording of LV and aortic pressures.

(e) Following diltiazem infusion at the same paced heart rate as in (a) and (b) during recording of LV pressures.

(f) Following diltiazem infusion at the same paced heart rate as in (a) and (b) during a second LV cineangiogram. The patient position was left unchanged in relation to the $\mathrm{x}$-ray equipment during both angiograms.

\section{Analysis of pressure-derived indices during systole and diastole}

Pressure measurements suitable for analysis before and after diltiazem administration were obtainable in 15 patients during spontaneous heart rate and in 10 patients during paced heart rate. Pressure measurements during angiography were obtainable in each of the 13 patients with LV angiograms suitable for regional wall motion analysis (see below).

LV pressure measured by micromanometer was digitized at 250 samples/s. Peak LV pressure, LV end-diastolic pressure (LVEDP), peak positive $d P / d t$, peak negative $d P / d t$, and the relationship between $d P / d t$ pressure and total pressure linearly extrapolated to pressure $=0$ $\left(\dot{V}_{\max }\right)$ were computed on-line after a data acquisition of $20 \mathrm{~s}$.

TABLE 1. Clinical data

\begin{tabular}{|c|c|c|c|c|c|}
\hline Name & Age & Sex & $\begin{array}{c}\text { Coronary } \\
\text { lesion }\end{array}$ & $\begin{array}{l}\text { Coronary } \\
\text { score }^{a}\end{array}$ & $\begin{array}{c}\text { Previous } \\
\text { MI }\end{array}$ \\
\hline FW & 59 & M & $3 \mathrm{VD}$ & 17 & - \\
\hline GvG & 56 & M & $2 \mathrm{VD}$ & 10.5 & Posterolateral \\
\hline AS & 67 & M & $3 \mathrm{VD}$ & 8.5 & Inferior \\
\hline JS & 61 & $\mathrm{M}$ & $2 \mathrm{VD}$ & 9.5 & - \\
\hline HJP & 56 & $\mathrm{M}$ & $2 \mathrm{VD}$ & 12 & Anterior \\
\hline SK & 61 & $\mathrm{M}$ & $\mathrm{CABG}+3 \mathrm{VD}$ & 33.5 & - \\
\hline HV & 62 & M & $\mathrm{CABG}+3 \mathrm{VD}$ & 21 & History + \\
\hline AHS & 62 & $\mathrm{M}$ & 0 & 0 & - \\
\hline JV & 68 & M & $3 \mathrm{VD}$ & 20 & - \\
\hline JS & 62 & $\mathrm{M}$ & $3 \mathrm{VD}$ & 14.5 & Anteroseptal \\
\hline WJZ & 54 & $\mathrm{M}$ & Main stem & & - \\
\hline DR & 53 & M & 2 VD & 4.5 & - \\
\hline PJJD & 61 & $\mathrm{M}$ & $2 \mathrm{VD}$ & 6.5 & $\begin{array}{l}\text { History }+ \text {, } \\
\text { ECG normal }\end{array}$ \\
\hline LD & 60 & M & $3 \mathrm{VD}$ & 27 & - \\
\hline HJD & 59 & M & $3 \mathrm{VD}$ & 18.5 & $\begin{array}{l}\text { History }+, \\
\text { ECG normal }\end{array}$ \\
\hline
\end{tabular}

M, male; CABG, coronary artery bypass graft; MI, myocardial infarction; VD, vessel disease; ECG, electrocardiogram.

${ }^{a}$ Calculated according to Leaman et al. (9). 


\section{Determination of relaxation parameters}

For off-line analysis of LV pressure relaxation an updated version of the beat-to-beat program described previously $(11,12)$ was used with the following definitions: (a) pressure at the beginning of isovolumetric relaxation $\left(P_{\mathrm{b}}\right)$ is the pressure at the point at which $d P / d t$ is minimal (maximum negative $d P / d t$ ); and (b) pressure at the end of isovolumetric relaxation $\left(P_{\mathrm{e}}\right)$ is the pressure less than or equal to the previous end-diastolic pressure, but not $<1$ $\mathrm{mm} \mathrm{Hg}$. Although it is possible that the latter definition may result in $P_{\mathrm{e}}$ being measured just after mitral valve opening, estimation of the time constants by more stringent criteria, such as end-diastolic pressure $+10 \mathrm{~mm} \mathrm{Hg}$, did not result in a significantly better estimation.

A semilogarithmic model used for the off-line, beat-tobeat calculation of the relaxation parameters was $P(\mathrm{t})=$ $P_{0} \mathrm{e}^{-\mathrm{tT}}$, where $P$ is pressure; $P_{0}$ is equivalent to $P_{\mathrm{b}}$ when a true exponential decay is present starting from the time of peak negative $d P / d t$; the $P_{0}$ and $\mathrm{T}$ parameters were estimated from a linear least squares fit of $\ln$ in $P=-\mathrm{t} /$ $T+\ln P_{0}$. In addition, a biexponential fit for isovolumic relaxation was determined, characterized by two exponential time constants - the fit for the first $40 \mathrm{~ms}(\mathrm{n}=$ $8), T_{1}$, and the fit after the first $40 \mathrm{~ms}, \mathrm{~T}_{2}(13)$.

\section{Coronary blood flow measurements and myocardial oxygen consumption}

In 11 patients CS flow and, in 10 of these, GCV flow were measured via the continuous thermodilution method of Ganz. Arterial, CS, and GCV blood samples were simultaneously withdrawn for the determination of blood $\mathrm{O}_{2}$ content (Lex- $\mathrm{O}_{2}$-CON, Lexington Instruments Corp.). Global and regional myocardial $\mathrm{O}_{2}$ consumption were calculated as a product of blood flow and arterial $\mathrm{CS}_{2}$ content difference.

Regional (GCV) and/or global (CS) coronary vascular resistance were derived from the ratio of mean aortic pressure to coronary venous blood flow.

\section{Analysis of global and regional LV function}

Global and regional LV functions were studied from the $30^{\circ}$ right anterior oblique LV cineangiogram with an automated hardwired endocardial contour detector linked to a minicomputer (14). For each analyzed cineframe, LV volumes were computed according to Simpson's rule. After the end-diastolic and end-systolic frames were determined, stroke volume, global ejection fraction, and total cardiac index were determined. In Figure 1A an example of the end-diastolic and end-systolic contours of the left ventriculogram, as displayed by the analysis system, is shown. Systolic regional wall displacement is determined along a system of 20 coordinates based on the pattern of actual endocardial wall motion in normal individuals (15), and generalized as a mathematical expression amenable to automatic data processing $(16,17)$. For each segment, segmental volume is computed from the local radius (R) and the height of each segment $(1 / 10$ of LV long axis length) (L) according to the formula $1 / 20 \pi R^{2} L$. When normalized for end-diastolic volume, the systolic segmental volume change can be considered a parameter of regional pump function (Fig. 1B). During systole this parameter expresses quantitatively the contribution of a particular segment to global ejection fraction or CREF (16) (Fig. 1C).
The sum of the values for all 20 segments equals the global ejection fraction. The cross-hatched zones in Figure 1D represent the segmental CREF values between the 10th and 90th percentiles, as determined in 20 normal individuals. The segmental CREF values in the anterobasal (segments 1-5), anterolateral (segments 5-9), apical (segments 9, 10, 19, and 20), inferior (segments 1519), and posterobasal (segments 11-15) wall regions were analyzed. Interpretable LV angiograms were available in 13 patients, and a total of 260 segments were analyzed in these patients; four patients had abnormal wall motion in the inferior region, three patients in the anterior region, and six in both regions (Fig. 2).

\section{Statistics}

Results are expressed as means \pm SD or SE. Group data before and after diltiazem administration were compared by paired Student's $t$ test. A $p$ value of $<0.05$ was considered statistically significant.

\section{RESULTS}

\section{Measurements during spontaneous heart rate}

During spontaneous heart rate, diltiazem produced a significant decrease in peak systolic pressure without an increase in heart rate (Fig. 3). At the end of the infusion, peak systolic pressure decreased from 145 to $110 \mathrm{~mm} \mathrm{Hg}\left(-24 \% ; p<10^{-6}\right)$ and heart rate changed from 73 to 69 beats/min ( $-5 \%$; NS). The end-diastolic pressure did not change (from 19 to $18 \mathrm{~mm} \mathrm{Hg}$; NS). Although calculated $\dot{V}_{\max }$ increased slightly $(+12 \%$; p $<0.05)$, peak velocity of contractile elements remained unchanged.

There were no changes in the time constants of relaxation before and after administration of diltiazem in these patients (Table 2).

CS blood flow did not change (from $165 \pm 62$ to $149 \pm 45 \mathrm{ml} / \mathrm{min}$; NS). GCV blood flow remained unchanged (from $58 \pm 11$ to $61 \pm 21 \mathrm{ml} / \mathrm{min}$ ). As the mean aortic pressure decreased, from $107 \pm 12$ to $75 \pm 5 \mathrm{~mm} \mathrm{Hg}\left(\mathrm{p}<10^{-6}\right)$, the global and regional coronary vascular resistance diminished, respectively, from $0.82 \pm 0.41$ to $0.56 \pm 0.16 \mathrm{~mm} \mathrm{Hg} / \mathrm{ml} /$ $\min (\mathrm{p}<0.02)$ and from $2.05 \pm 0.54$ to $1.34 \pm 0.41$ $\mathrm{mm} \mathrm{Hg} / \mathrm{ml} / \mathrm{min}\left(\mathrm{p}<10^{-3}\right)$ (Fig. 4). The mean arterio-CS and GCV $\mathrm{O}_{2}$ saturation differences fell from $9.5 \pm 1.0$ to $8.5 \pm 1.3 \mathrm{ml} \%(\mathrm{p}<0.005)$ and from $9.9 \pm 1.6$ to $9.0 \pm 2.1 \mathrm{ml} \%$ ( $<<0.05$ ), respectively. This significant decrease in arterio-CS $\mathrm{O}_{2}$ difference not associated with an increase in CS blood flow, resulted in a significant decrease from $14.9 \pm 4.7$ to $12.1 \pm 2.3 \mathrm{ml} / \mathrm{min}(\mathrm{p}<0.02)$ in global myocardial $\mathrm{O}_{2}$ consumption (Fig. 5, Table 3).

\section{Measurements during matched, paced heart rate}

At matched heart rate, in a subset of 10 patients, although $\dot{V}_{\max }$ performed before and after diltiazem infusion did not differ significantly, the end-systolic pressure-volume index significantly decreased (from $3.74 \pm 1.6$ to $3.18 \pm 0.97 \mathrm{~mm} \mathrm{Hg} / \mathrm{ml} ;-15 \%$; $\mathrm{p}<0.05$ ). The monoexponential time constant, $\mathrm{T}$, 

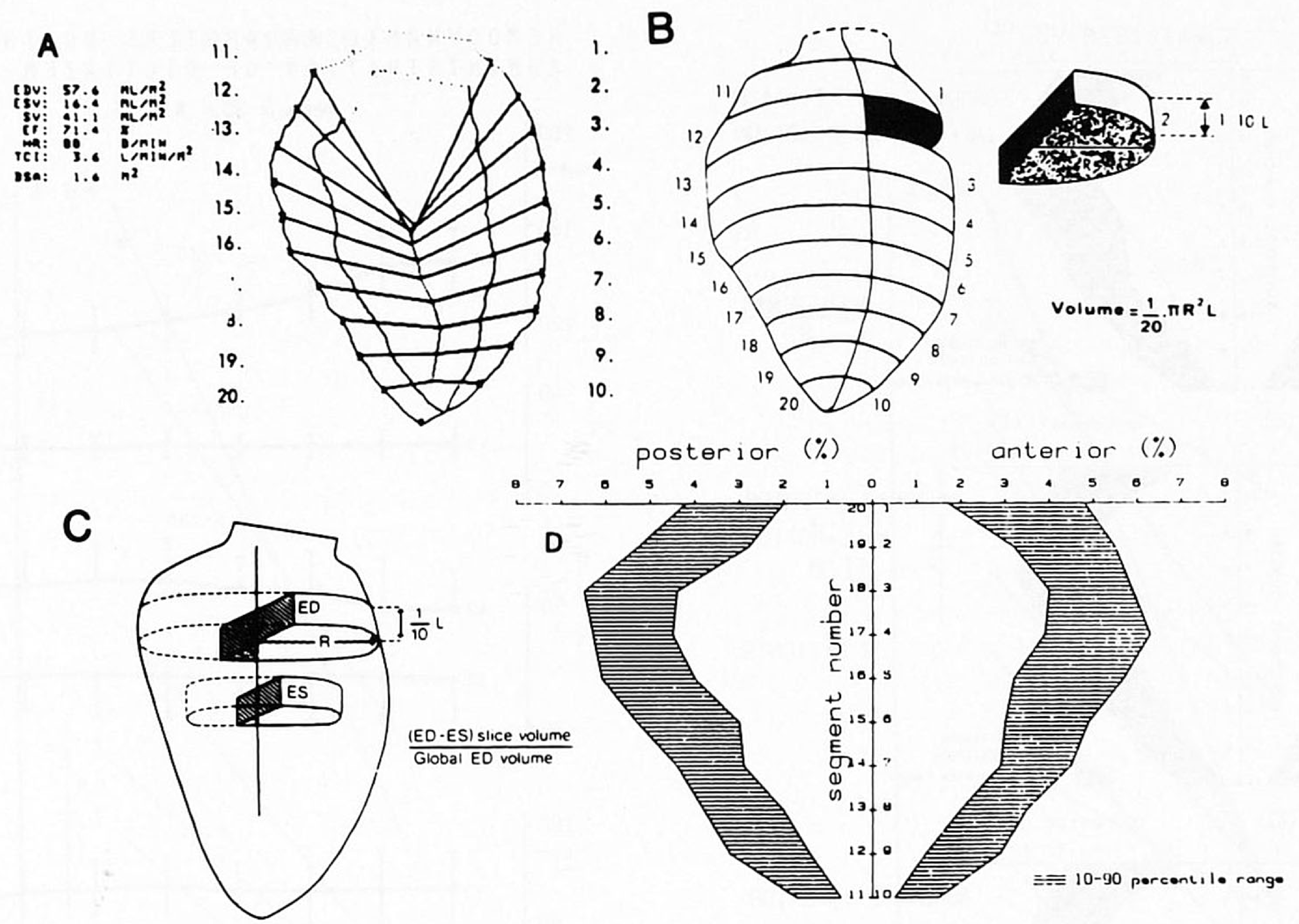

FIG. 1. A: Example of computer output showing the end-diastolic (ED) and end-systolic (ES) contours of the $30^{\circ}$ right anterior oblique left ventriculogram and the system of coordinates along which left ventricular segmental wall displacement is determined. The corresponding volume data, ejection fraction (EF), and other parameters are shown in the upper left corner. B: The left ventricular ED cavity is divided into 20 half-slices. The volume of each half-slice is computed according to the given formula; $R$ is radius and $L$ is left ventricular long axis length. C: The regional contribution to global ejection fraction (CREF) is determined from the systolic decrease of volume of the half-slice that corresponds to a particular wall segment. The systolic volume change is mainly a consequence of the decrease of $R$ of the half-slice, which is expressed by the $x$-component of the displacement vector. D: The shaded zones represent the 10th-90th percentile area of CREF values in normal individuals. On the $x$-axis the CREF values of the anterior and inferoposterior wall areas are displayed (\%), while on the $y$-axis the segment numbers of the anterior wall $(1-10)$ and of the inferoposterior wall (11-20) are depicted. EDV, end-diastolic volume; ESV, end-systolic volume; $\mathrm{SV}$, stroke volume; HR, heart rate; TCl, total cardiac index; BSA, body surface area.

was not significantly shortened after administration of diltiazem, while $T_{1}$, the first biexponential time constant, was significantly shortened (Table 2 ).

Table 4 shows changes in LV volumes resulting from the drug administration at matched heart rate. A $2 \%$ decrease in end-diastolic volume (NS) and $7 \%$ decrease in end-systolic volume $(\mathrm{p}<0.05)$ resulted in a nonsignificant increase of $3 \%$ in stroke volume (from 38 to $39 \mathrm{ml} / \mathrm{m}^{2}$; NS). The LVEDP and circumferential fiber shortening rate remained unchanged, in spite of a marked reduction in peripheral vascular resistance (from 1,566 \pm 290 to 1,216 \pm 248 dyne $\mathrm{s} \mathrm{cm}^{-5} ; \mathrm{p}<10^{-5}$ ) and in mean aortic pressure.

From the regional wall displacement data, the CREF was computed for each segment; 95 of 260 were found abnormal, with a CREF value inferior to the 10th percentile. Before diltiazem infusion, the sum of the CREF of these abnormal segments amounted to $17 \pm 5 \%$ of the global ejection fraction, while the normal segments contributed $37.9 \pm$ $12 \%$ of the ejection fraction (Table 5).

Following diltiazem administration, the sum of CREF of the initially abnormal segments did not change significantly, from $17 \pm 5$ to $18 \pm 7 \%$, and the sum of CREF of the normal segments $(n=165)$ also remained unchanged (from $37.9 \pm 12$ to 37.5 $\pm 9 \%$; NS). The regional functional changes of patients with inferior and/or anterior wall dysfunction are shown in Figure 2.

\section{DISCUSSION}

The aim of our study was to detect acute hemodynamic changes that might appear following a rapid injection of high-dose diltiazem, and to investigate if the beneficial unloading effects at this dose might not be excessively offset by the drug's known direct negative inotropic effects.

The hemodynamic effect of intravenous diltiazem can be studied by two techniques: the single bolus injection and the initial bolus followed by continuous infusion. We used the single bolus injection for two reasons. First, it could be desirable in an acute ischemic situation to give diltiazem as a bolus. Second, there is presently no assurance that a continuous infusion provides stable hemodynamic effects $(18,19)$.

With acute high-dose diltiazem administration, we found a decrease in arterial pressure with no net 


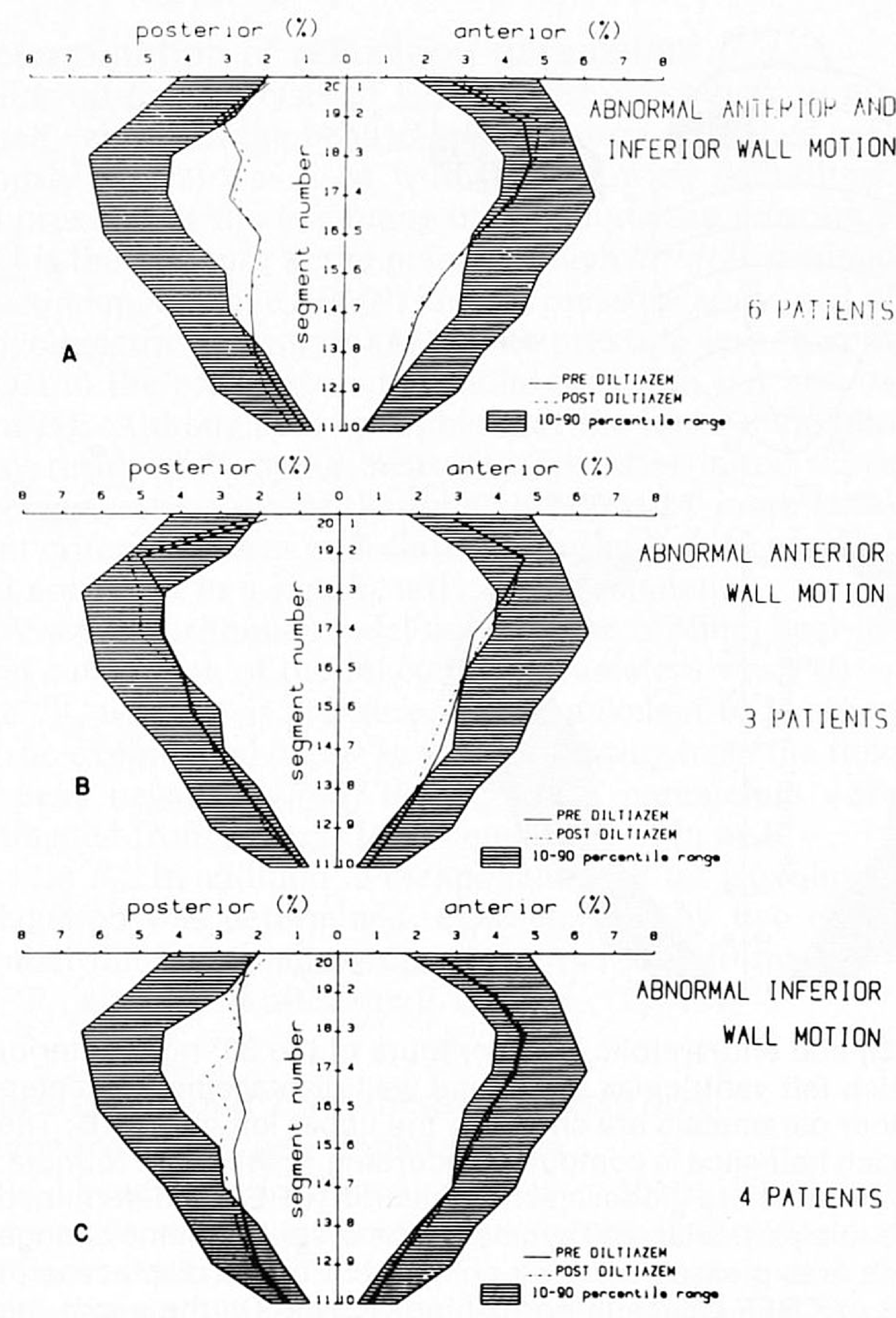

FIG. 2. Illustration of left ventricular regional wall motion in 13 patients. A: Six patients with abnormal anterior and inferior wall motion. B: Three patients with abnormal anterior wall motion. C: Four patients with abnormal inferior wall motion.

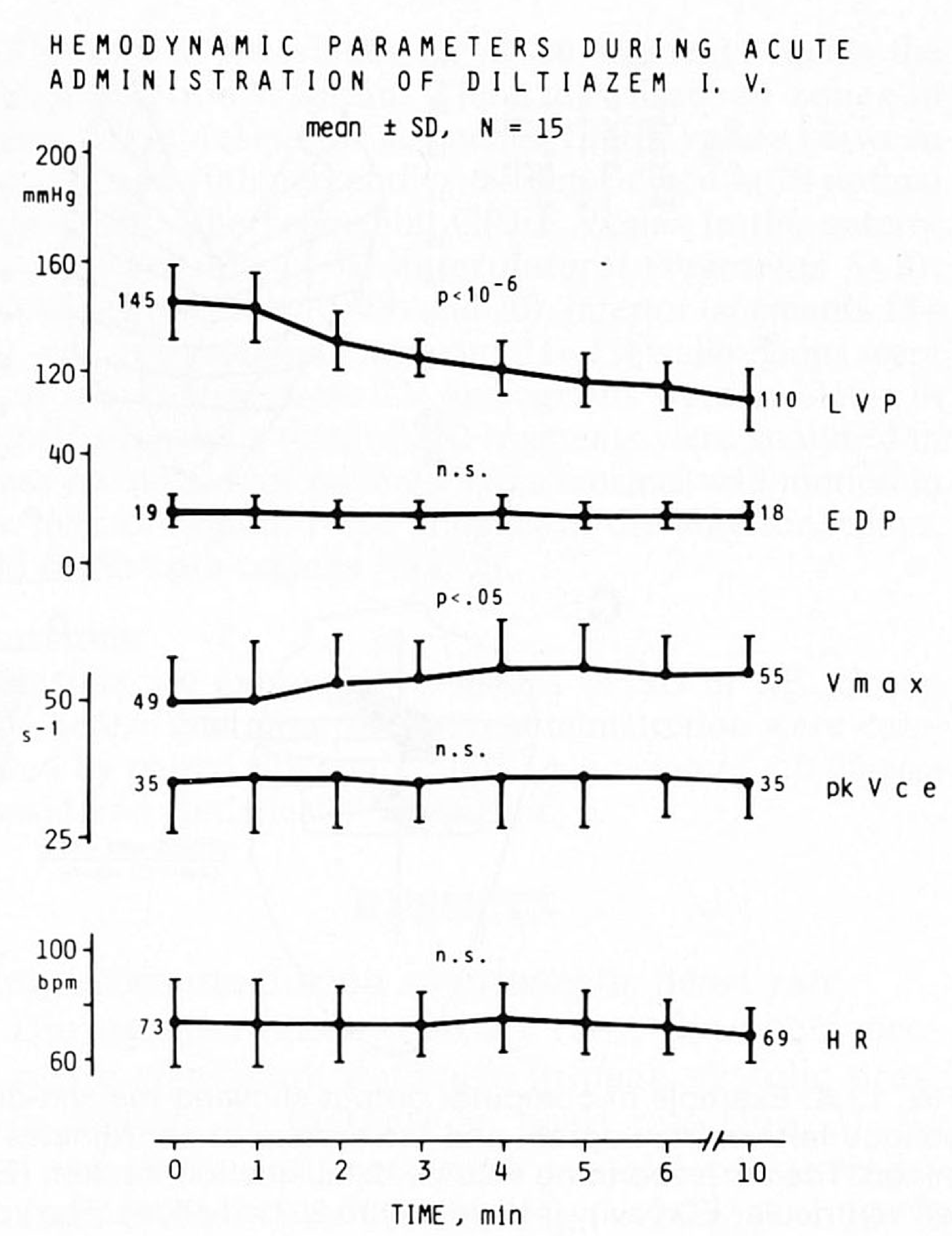

FIG. 3. Serial hemodynamic changes during acute administration of intravenous diltiazem. LVP, left ventricular peak systolic pressure; EDP, left ventricular end-diastolic pressure; $\dot{V}_{\text {max }}, V_{c e}$ derived from total pressure lineally extrapolated to pressure $=0 ; \mathrm{Pk} \mathrm{V}_{\text {ce }}$, peak velocity of contractile elements; HR, heart rate. Values represent means $\pm S D$.

TABLE 2. Isovolumic relaxation before and after diltiazem administration

\begin{tabular}{lccrc}
\hline & $\begin{array}{c}\text { Before } \\
\text { diltiazem }\end{array}$ & $\begin{array}{c}\text { After } \\
\text { diltiazem }\end{array}$ & $\Delta \%$ & $\begin{array}{c}p \\
\text { value }\end{array}$ \\
\hline RR (ms) & $785 \pm 67$ & $786 \pm 68$ & 0 & NS \\
P & $887 \pm 139$ & $904 \pm 130$ & +2 & NS \\
NP & & & & \\
Peak $d P / d t\left(\mathrm{~mm} \mathrm{Hg} \mathrm{s}^{-1}\right)$ & $1,865 \pm 304$ & $1,526 \pm 197$ & -18 & $<0.002$ \\
P & $1,770 \pm 313$ & $1,484 \pm 162$ & -16 & $<0.001$ \\
NP & $45 \pm 4$ & $43 \pm 2$ & -4 & NS \\
T (ms) & $45 \pm 7$ & $45 \pm 6$ & 0 & NS \\
P & $48 \pm 5$ & $44 \pm 3$ & -8 & $<0.01$ \\
NP & $48 \pm 6$ & $47 \pm 5$ & -2 & NS \\
$T_{1}(\mathrm{~ms})$ & $43 \pm 5$ & $41 \pm 4$ & -5 & NS \\
P & $42 \pm 8$ & $43 \pm 9$ & +2 & NS \\
NP & & & & \\
$T_{2}$ (ms) & & & & \\
P & & & & \\
NP & & & & \\
\end{tabular}

$\mathrm{RR}$, cycle length; $d P / d t$, rate of change in left ventricular pressure; T, global time constant from the "semilogarithmic" model; $T_{1}$ and $T_{2}$, biexponential fitting $-T_{1}$ fit of first $40 \mathrm{~ms}, \mathrm{~T}_{2}$ fit after $40 \mathrm{~ms}$; $\mathrm{P}$, matched pacing $(\mathrm{n}=10)$; NP, spontaneous heart rate $(n=15)$.

Values represent means $\pm \mathrm{SD}$. 
CS RESISTANCE

$N=11$

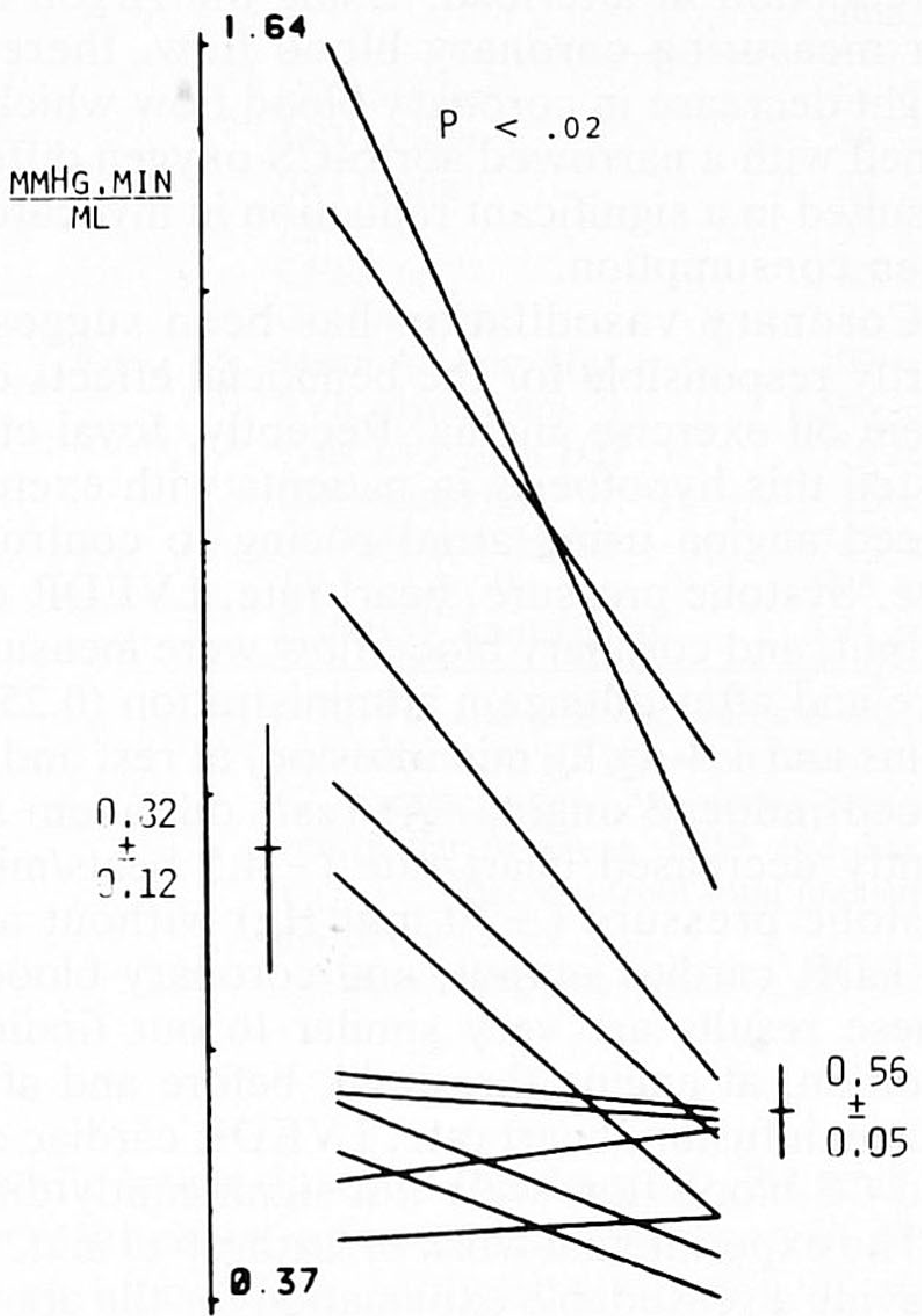

BEFORE

AFTER

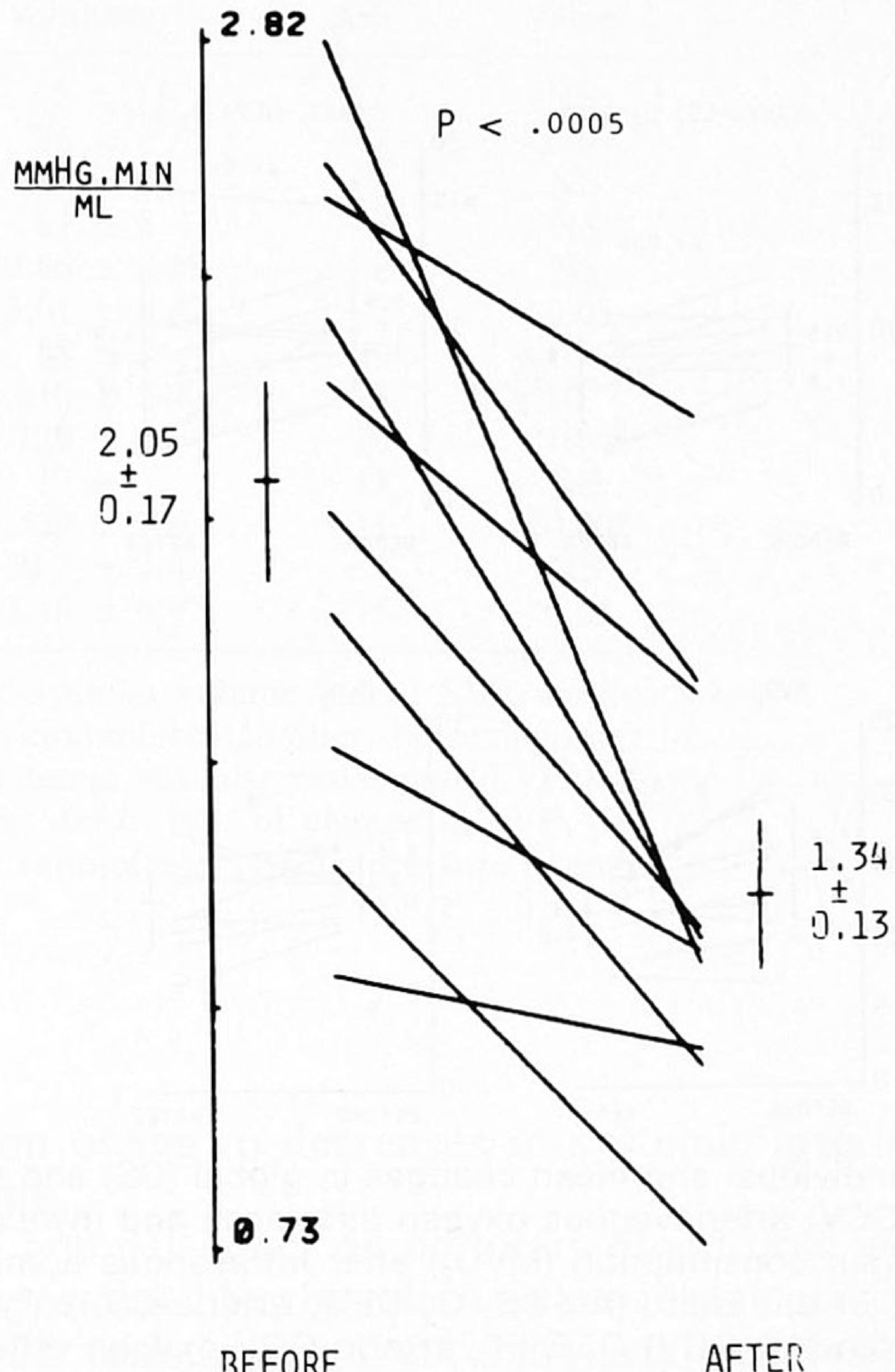

FIG. 4. Individual and mean changes in global (coronary sinus; CS) and regional (great cardiac vein; GCV) coronary vascular resistance after intravenous administration of diltiazem. CS resistance is calculated from CS blood flow. GCV resistance is calculated from GCV blood flow. Values represent means $\pm \mathrm{SE}$.

change in heart rate, LVEDP, or LV stroke volume. Myocardial oxygen consumption decreased. Decreases in both systemic arterial pressure and coronary vascular resistance occurred with no net improvement in coronary blood flow.

\section{Effect on coronary blood flow}

Following infusion of diltiazem, $30 \mu \mathrm{g} / \mathrm{kg} / \mathrm{min}$ i.v., in patients with coronary artery disease, Bourassa et al. (3) observed a slight but nonsignificant decrease in aortic pressure. Systemic vascular resistance, however, decreased by $20 \%$. Fifteen minutes after cessation of drug administration, the fall in blood pressure persisted and heart rate, which had remained unchanged during the infusion, began to decrease. LVEDP and cardiac index were unchanged during diltiazem administration. Coronary vascular resistance was observed to decrease, associated with an increase in CS blood flow. A doserelated reduction in myocardial oxygen uptake was also demonstrated. Oxygen consumption, on the other hand, was not altered significantly since the product of coronary blood flow and LV oxygen extraction did not change.

Bertrand et al. (6) reported that CS blood flow increased significantly by $\sim 12 \%$, along with a fall of $18 \%$ in coronary artery resistance, after the administration of $0.15 \mathrm{mg} / \mathrm{kg}$ diltiazem over $2 \mathrm{~min}$ followed by $0.05 \mathrm{mg} / \mathrm{kg}$ over $8 \mathrm{~min}$. As can be expected, these changes were not as marked as those observed after intracoronary injections of an identical bolus of $0.15 \mathrm{mg} / \mathrm{kg}$; coronary blood flow increased by $>20 \%$ together with a reduction in coronary resistance of $40 \%$.

At the end of a 5 -min infusion of $300 \mu \mathrm{g} / \mathrm{kg}$ over $5 \mathrm{~min}$ in patients with coronary disease, Biamino et al. (4) observed an increase in heart rate and cardiac output together with a sharp decrease in blood pressure and total peripheral resistance. LV filling pressure increased concomitantly and $d P / d t / P$ was reduced. Following these initial changes, heart rate decreased below the initial values, while a reduction in blood pressure and peripheral resistance persisted over a 15 -min period. These authors con- 

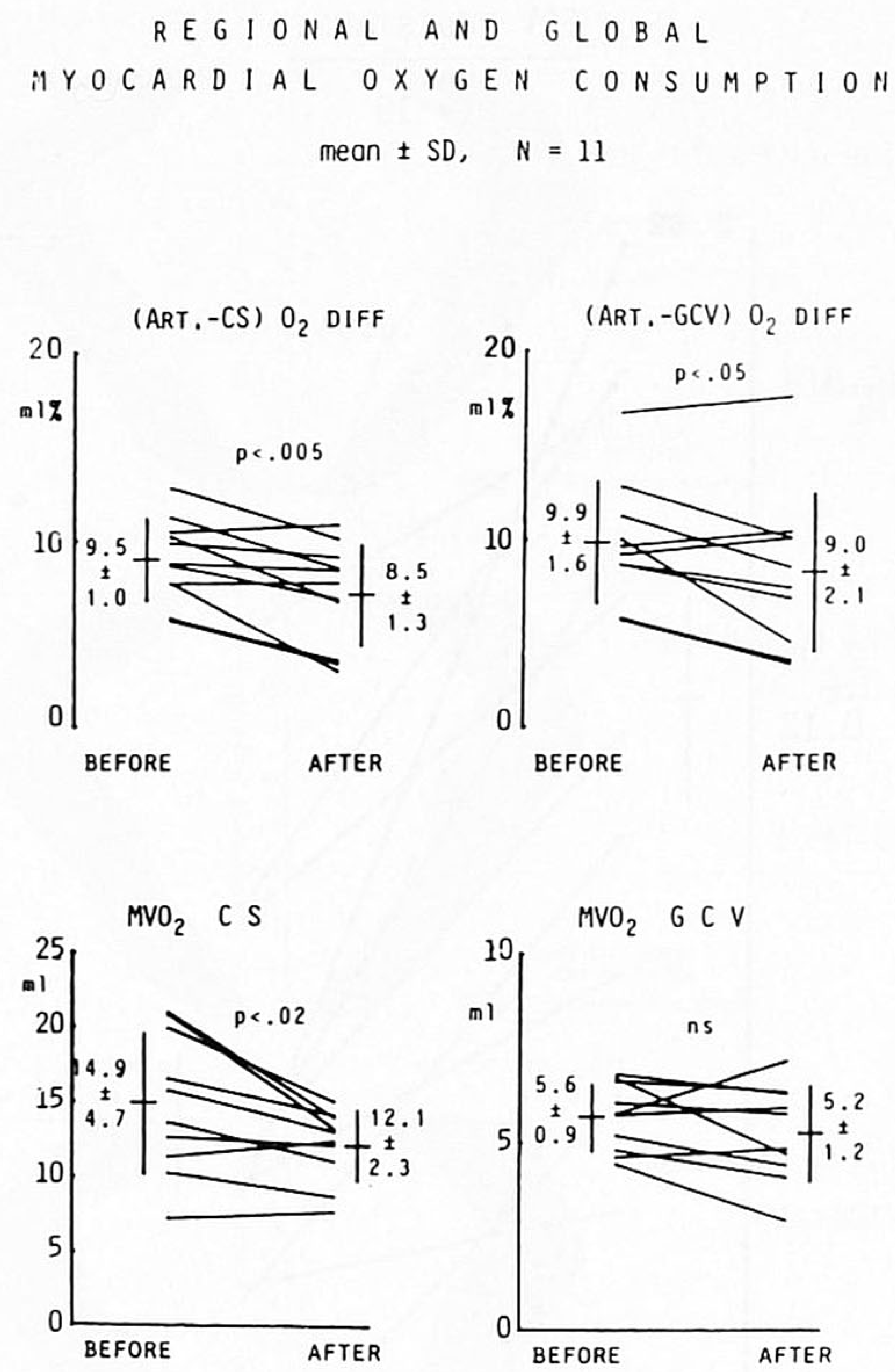

FIG. 5. Individual and mean changes in global (CS) and regional (GCV) arteriovenous oxygen difference and myocardial oxygen consumption $\left(\mathrm{MVO}_{2}\right)$ after intravenous administration of diltiazem. (Art-CS) $\mathrm{O}_{2}$ DIFF, arterio-CS oxygen difference; (Art-GCV) $\mathrm{O}_{2}$ DIFF, arterio-GCV oxygen difference; $\mathrm{MVO}_{2} \mathrm{CS}$ and $\mathrm{GCV}, \mathrm{MVO}_{2}$ calculated from oxygen content in blood samples obtained in aorta, CS, and GCV.

Values represent means \pm SD. CS and GCV as defined in Figure 4. cluded that the temporary increase in filling pressure might reflect a negative inotropic effect of the drug. However, this effect was counterbalanced by a reduction in afterload. Using the Argon method for measuring coronary blood flow, there was a slight decrease in coronary blood flow which, combined with a narrowed aorto-CS oxygen difference, resulted in a significant reduction in myocardial oxygen consumption.

Coronary vasodilation has been suggested as partly responsible for the beneficial effects of diltiazem on exercise angina. Recently, Joyal et al. (7) tested this hypothesis in patients with exercise-induced angina using atrial pacing to control heart rate. Systolic pressure, heart rate, LVEDP, cardiac output, and coronary blood flow were measured before and after diltiazem administration $(0.25-\mathrm{mg} / \mathrm{kg}$ bolus and $1.4-\mu \mathrm{g} / \mathrm{kg} / \mathrm{min}$ infusion) at rest and during paced-induced angina. At rest, diltiazem significantly decreased heart rate $(-4.5$ beats/min) and systolic pressure $(-20 \mathrm{~mm} \mathrm{Hg})$ without altering LVEDP, cardiac output, and coronary blood flow. These results are very similar to our findings. In addition, at angina threshold, before and after diltiazem infusion, heart rate, LVEDP, cardiac output, and CS blood flow were not significantly different.

The experimental work of Lathrop et al. (2) might provide a reasonable explanation for the apparently conflicting results of the different clinical hemodynamic studies mentioned above. In the open-chest $\mathrm{dog}$, they demonstrated that large intravenous bolus doses of diltiazem $(600$ and $1,000 \mu \mathrm{g} / \mathrm{kg})$ reduced the blood pressure but failed to increase the blood

TABLE 3. $\mathrm{MVO}_{2}$, coronary flow, and resistance following diltiazem administration

\begin{tabular}{|c|c|c|c|c|c|}
\hline & & $\begin{array}{c}\text { Before } \\
\text { diltiazem }\end{array}$ & $\begin{array}{c}\text { After } \\
\text { diltiazem }\end{array}$ & $\Delta \%$ & $\begin{array}{c}p \\
\text { value }\end{array}$ \\
\hline CS flow $(\mathrm{ml} / \mathrm{min})$ & $(\mathrm{n}=11)$ & $165 \pm 62$ & $149 \pm 45$ & -10 & NS \\
\hline GCV flow (ml/min) & $(n=10)$ & $58 \pm 11$ & $61 \pm 21$ & +5 & NS \\
\hline $\mathrm{O}_{2}$ cont art $(\mathrm{ml} \%)$ & $(\mathrm{n}=11)$ & $19 \pm 1.1$ & $18.7 \pm 1.3$ & -2 & NS \\
\hline $\mathrm{O}_{2}$ cont $\mathrm{CS}(\mathrm{ml} \%)$ & $(\mathrm{n}=11)$ & $9.2 \pm 1.5$ & $10.1 \pm 1.8$ & +10 & $<0.02$ \\
\hline $\mathrm{O}_{2}$ cont $\mathrm{GCV}(\mathrm{ml} \%)$ & $(\mathrm{n}=10)$ & $9 \pm 1.5$ & $9.6 \pm 1.6$ & +7 & $<0.05$ \\
\hline (art CS) $\mathrm{O}_{2}$ diff $(\mathrm{ml} \%)$ & $(\mathrm{n}=11)$ & $9.5 \pm 1.0$ & $8.5 \pm 1.3$ & -11 & $<0.005$ \\
\hline (art GCV) $\mathrm{O}_{2}$ diff $(\mathrm{ml} \%)$ & $(\mathrm{n}=10)$ & $9.9 \pm 1.6$ & $9.0 \pm 2.1$ & -9 & $<0.05$ \\
\hline $\mathrm{MVO}_{2} \mathrm{CS}(\mathrm{ml} / \mathrm{min})$ & $(\mathrm{n}=11)$ & $14.9 \pm 4.7$ & $12.1 \pm 2.3$ & -19 & $<0.02$ \\
\hline $\mathrm{MVO}_{2} \mathrm{GCV}(\mathrm{ml} / \mathrm{min})$ & $(\mathrm{n}=10)$ & $5.6 \pm 0.9$ & $5.2 \pm 1.2$ & -7 & NS \\
\hline Mean AoP (mm Hg) & $(\mathrm{n}=11)$ & $107 \pm 12$ & $75 \pm 5$ & -30 & $<10^{-6}$ \\
\hline \multicolumn{6}{|l|}{ Resist CS } \\
\hline$(\mathrm{mm} \mathrm{Hg} / \mathrm{ml} / \mathrm{min})$ & $(\mathrm{n}=11)$ & $0.82 \pm 0.41$ & $0.56 \pm 0.16$ & -32 & $<0.02$ \\
\hline $\begin{array}{l}\text { Resist GCV } \\
\text { (mm Hg/ml/min) }\end{array}$ & $(n=10)$ & $2.05 \pm 0.54$ & $1.34 \pm 0.41$ & -35 & $<0.0005$ \\
\hline
\end{tabular}

$\mathrm{CS}$, coronary sinus; $\mathrm{GCV}$, great cardiac vein; $\mathrm{O}_{2}$ cont, oxygen content; $\mathrm{MVO}_{2}$, global (CS) or regional (GCV) myocardial oxygen consumption; AoP, aortic pressure; Resist, resistance.

Values represent means $\pm \mathrm{SD}$. 
TABLE 4. Left ventricular performance before and after diltiazem administration during matched, pacing heart rate

\begin{tabular}{lcccc}
\hline & $\begin{array}{c}\text { Before } \\
\text { diltiazem }\end{array}$ & $\begin{array}{c}\text { After } \\
\text { diltiazem }\end{array}$ & $\Delta \%$ & $\begin{array}{c}p \\
\text { value }\end{array}$ \\
\hline EDVI $\left(\mathrm{ml} / \mathrm{m}^{2}\right)$ & $66 \pm 10$ & $65 \pm 11$ & -2 & $\mathrm{NS}$ \\
ESVI $\left(\mathrm{ml} / \mathrm{m}^{2}\right)$ & $28 \pm 8$ & $26 \pm 8$ & -7 & $<0.05$ \\
SVI $\left(\mathrm{ml}^{2}\right)$ & $38 \pm 7$ & $39 \pm 6$ & +3 & $\mathrm{NS}$ \\
EF $(\%)$ & $58 \pm 8$ & $61 \pm 8$ & +4 & $\mathrm{NS}$ \\
CFSR $\left(\mathrm{s}^{-1}\right)$ & $0.80 \pm 0.22$ & $0.86 \pm 0.18$ & +8 & $\mathrm{NS}$ \\
CI $\left(\mathrm{L} / \mathrm{min} / \mathrm{m}^{2}\right)$ & $2.82 \pm 0.38$ & $3.01 \pm 0.42$ & +7 & $<0.03$ \\
Mean Ao $(\mathrm{mm} \mathrm{Hg})$ & $109 \pm 12$ & $88 \pm 7$ & -19 & $<10^{-5}$ \\
SVR $\left.(\mathrm{dyne} \mathrm{s} \mathrm{cm})^{-5}\right)$ & $1,566 \pm 290$ & $1,216 \pm 248$ & -23 & $<10^{-5}$ \\
Peak LVP $(\mathrm{mm} \mathrm{Hg})$ & $159 \pm 20$ & $128 \pm 13$ & -20 & $<10^{-4}$ \\
EDP $(\mathrm{mm} \mathrm{Hg})$ & $19 \pm 9$ & $17 \pm 5$ & -11 & $\mathrm{NS}$ \\
$+d P / d t(\mathrm{~mm} \mathrm{Hg} / \mathrm{s})$ & $1,717 \pm 303$ & $1,529 \pm 205$ & -11 & $<0.002$ \\
TP $\dot{\text { max }}\left(\mathrm{s}^{-1}\right)$ & $47.6 \pm 6.7$ & $50.7 \pm 7.4$ & +7 & $\mathrm{NS}$ \\
ESP/ESV $(\mathrm{mm} \mathrm{Hg} / \mathrm{ml})$ & $3.74 \pm 1.6$ & $3.18 \pm 0.97$ & -15 & $<0.05$ \\
\hline
\end{tabular}

EDVI, end-diastolic volume index; ESVI, end-systolic volume index; SVI, stroke volume index; EF, ejection fraction; CFSR, mean circumferential fiber shortening rate; CI, cardiac index; Ao, aortic pressure; SVR, systemic vascular resistance; LVP, left ventricular pressure; EDP, end-diastolic pressure; $d P / d t$, rate of change in LVP; TP $\dot{V}_{\max }, \dot{V}_{\max }$ derived from total pressure; ESP/ESV, ratio of end-systolic pressure to endsystolic volume.

Values represent means $\pm \operatorname{SD}(n=15)$.

flow, while lower doses of the drug $(10,30$, and 100 $\mu \mathrm{g} / \mathrm{kg}$ ) resulted in an immediate increase in mean coronary blood flow, without alteration in mean blood pressure.

The varying effect on coronary blood flow observed in the various clinical studies might then be dose and infusion rate related. Changes in coronary vascular resistance may be accounted for by the following three factors: (a) diltiazem-mediated direct coronary artery vasodilation; (b) autoregulation of blood flow secondary to changes in coronary artery perfusion pressure and myocardial oxygen consumption; and (c) reflex sympathetic stimula- tion owing to decreases in systemic arterial pressure.

The net effect on coronary blood flow would be determined by the relative changes in coronary vascular resistance and coronary artery perfusion pressure. High serum levels of diltiazem could result in a marked reduction in systemic blood pressure and no increase in coronary blood flow despite a decreased coronary vascular resistance. Low serum levels of diltiazem with a minimal reduction in arterial perfusion pressure, however, could permit coronary blood flow to increase.

From the investigations mentioned above, it can

TABLE 5. Normal and abnormal regional contributions to global ejection fraction (CREF)

\begin{tabular}{|c|c|c|c|c|c|c|c|}
\hline \multicolumn{4}{|c|}{ Abnormal CREF } & \multicolumn{4}{|c|}{ Normal CREF } \\
\hline \multicolumn{2}{|c|}{ Number of segments } & \multicolumn{2}{|c|}{ Sum of CREF ${ }^{a}$} & \multicolumn{2}{|c|}{ Number of segments } & \multicolumn{2}{|c|}{ Sum of CREF ${ }^{a}$} \\
\hline Before & After & Before & After & Before & After & Before & After \\
\hline 8 & 7 & 18.6 & 21.5 & 12 & 13 & 34.5 & 36.3 \\
\hline 6 & 3 & 17.8 & 19.1 & 14 & 17 & 40.6 & 41.7 \\
\hline 4 & 6 & 12.5 & 12.0 & 16 & 14 & 51.7 & 48.9 \\
\hline 12 & 13 & 18.5 & 13.5 & 9 & 7 & 23.9 & 23.3 \\
\hline 8 & 7 & 24.5 & 28.4 & 12 & 13 & 33.2 & 34.8 \\
\hline 9 & 11 & 12.3 & 12.8 & 11 & 9 & 37.9 & 36.0 \\
\hline 6 & 3 & 17.4 & 15.2 & 14 & 17 & 40.2 & 41.3 \\
\hline 10 & 7 & 21.3 & 21.9 & 10 & 13 & 27.8 & 28.2 \\
\hline 7 & 8 & 17.0 & 18.4 & 13 & 12 & 38.4 & 38.2 \\
\hline 1 & 4 & 5.2 & 3.9 & 19 & 16 & 70.6 & 56.8 \\
\hline 11 & 8 & 22.1 & 25.6 & 9 & 12 & 23.6 & 29.2 \\
\hline 5 & 6 & 10.9 & 13.4 & 15 & 14 & 41.3 & 39.4 \\
\hline 9 & 3 & 23.4 & 29.5 & 11 & 17 & 28.8 & 32.7 \\
\hline 95 & 86 & $17.1 \pm 5.5$ & $18.1 \pm 7$ & 165 & 174 & $37.9 \pm 12$ & $37.5 \pm 9$ \\
\hline
\end{tabular}

${ }^{a} \mathrm{p}=$ nonsignificant 
be concluded that diltiazem tends to decrease myocardial oxygen consumption. Increased oxygen delivery would not appear to be necessary to prevent exercise-induced angina by diltiazem.

It should be emphasized that diltiazem in our study was given as a short infusion without a subsequent continuous infusion and the coronary blood flow measurements were made 2-3 min later. Several experimental or clinical studies $(2,8,20)$ have shown that the coronary hemodynamic response to single-bolus injections of diltiazem may be largely dissipated $3 \mathrm{~min}$ following intravenous drug administration.

\section{Effect on the inotropic and chronotropic states}

Substantial information in isolated cardiac strips published by numerous laboratories indicates that the calcium channel blocking drugs have a pronounced negative inotropic action. In fact, by definition, they should have. In the guinea pig, nifedipine consistently has the most potent negative inotropic action, followed by verapamil and diltiazem. This is true for isolated atria, ventricle, and whole hearts (21). In the intact conscious dog, verapamil maintains a significant dose-dependent negative inotropy which is not significantly affected by the autonomic nervous system. In contrast, diltiazem produces little inotropic effect in conscious dog and is unaffected by autonomic blockade (22).

In our study, although systolic isovolumic indices overall were without any consistent change, LVEDP did not decrease and stroke volume did not increase despite a marked decrease in afterload. In addition, the small but significant decrease observed in the end-systolic pressure/volume ratio seems most likely to represent an intrinsic negative inotropic effect of diltiazem which could more specifically affect the local area having a depressed myocardial function. Because the drug is also a powerful peripheral vasodilator the intrinsic myocardial depressant effect is attenuated or even nullified by its salutary influence on ventricular afterload.

In spite of peripheral effects, which result in decreased oxygen demand, we found no evidence that diltiazem improves left ventricular asynergy in patients with coronary artery disease, since $90.5 \%$ of all asynergic segments remained unchanged and only $9.4 \%$ did actually improve. One would expect an improvement in such areas if the muscle is still viable and if the drug has no intrinsic negative inotropic effect.

It is also unlikely that diltiazem's potent in vitro coronary vasodilating action would contribute to an improvement in ventricular function through augmented blood supply. On the contrary, our results suggest that diltiazem administration (by decreasing coronary artery perfusion pressure and myocardial metabolic demand) could actually lead to a decrease in coronary flow.

We found that diltiazem caused a highly significant drop in blood pressure and systemic vascular resistance during the short infusion, presumably because of the direct relaxant action of diltiazem on the arterial smooth muscle-an effect which has been repeatedly demonstrated in vitro and in vivo. A drop of this magnitude in blood pressure should, however, elicit reflex tachycardia. We observed no increase in heart rate, suggesting that reflex sympathetic stimulation was offset by a direct negative chronotropic property of diltiazem.

Diltiazem is known to prolong the spontaneous sinus cycle length (23). Although this result is predicted by the effects of calcium antagonism on action potentials of slow channel-dependent tissue (24-26) and is consistent with isolated tissue studies (27), it is different from the shortening of sinus cycle length reported after acute administration of nifedipine $(28,29)$ or verapamil $(30,31)$. Possible explanations for these differences include greater direct effect on sinoatrial node function (32), less hypotensive effect (33), and nonspecific sympathetic blocking activity (25) with diltiazem.

\section{Effect on isovolumic relaxation}

$\mathrm{LV}$ isovolumic relaxation time is often abnormally prolonged in patients with coronary artery disease and regional asynergy $(13,34,35)$. In the present study, at a paced heart rate, the intravenous administration of diltiazem shortened some of the most sensitive indexes of isovolumic relaxation, such as the time constant for the first $40 \mathrm{~ms}$ of the relaxation phase. However, two major determinants of relaxation, namely, end-systolic pressure and volume were also affected by the intravenous administration of diltiazem, so that the shortening of the time constant might be related to this hemodynamic change and not necessarily reflect an intrinsic improvement of the relaxation of the heart muscle. Nevertheless, in vitro studies have suggested that the beneficial effect of diltiazem on LV isovolumic relaxation seems to be related to an improvement in ischemic myocardium, as reported by Weishaar et al. (36). Some clinical studies have shown that intravenous administration of diltiazem prevents the pacing- or exercise-induced elevation in filling pressure without changing LV systolic function (37-39), and clinical observation would suggest that diltiazem could improve LV diastolic function.

\section{Conclusion}

Acute high-dose bolus administration of diltiazem in this study led to a decrease in coronary and systemic vascular resistance and mean arterial pressure. Coronary blood flow remained unchanged. Findings consistent with a slight negative inotropic effect were observed. 
In the dose administered in this study, diltiazem did not produce any overt untoward effect and was most often hemodynamically outright beneficial. The safety of diltiazem in the doses used here remains to be determined in patients with acute LV dysfunction.

Acknowledgment: Dr. Jaski is supported by National Institutes of Health Training Grant 5-T32-HL0-7049.

\section{REFERENCES}

1. Kugita K, Inoue H, Ikezaki M, Takeo S. Synthesis of 1.5benzothiazepine derivative. I Chem Pharm Bull 1970;18: 2028-37.

2. Lathrop DA, Valle-Aguilera JR, Millard RW, et al. Comparative electrophysiologic and coronary hemodynamic effect of diltiazem, nisoldipine and verapamil in myocardial tissue. Am J Cardiol 1982;49:613-20.

3. Bourassa MG, Cote P, Theroux P, Tubau JF, Genain C, Waters DD. Hemodynamic and coronary flow following diltiazem administration in anesthetized dogs and humans. Chest 1980;78:224-30.

4. Biamino G, Oeff M, Prokein E, Schröder R. Verhalten von Hämodynamik und Koronardurchblutung nach intravenöser Gabe von Diltiazem bei koronarer Herzerkrankung. In: Bender F, Greeff K, eds. Calcium antagonisten zur Behandlung der Angina Pectoris, Hypertonie und Arrythmie. Amsterdam-Oxford-Princeton: Excerpta Medica, 1982:94-105.

5. Kenny J, Daly K, Bergman G, Kerkez S, Jackson G, Jewitt DE. The hemodynamic and metabolic effects of diltiazem, a new calcium antagonist, in patients with coronary artery disease. Ir J Med Sci 1982;151:29-30.

6. Bertrand ME, Dupuis BA, Lablanche JM, Tilmant PY, Thieleux FP. Coronary hemodynamics following intravenous or intracoronary injection of diltiazem in man. $J$ Cardiovasc Pharmacol 1982;4:695-9.

7. Joyal M, Cremer KF, Feldman L, Pieper JA, Pepine CJ. Is coronary vasodilation due to diltiazem responsible for relief of stress-induced angina? Circulation 1983;68:III-18.

8. Kober G, Schultz W, Scherer D, Kaltenbach M. Linksventrikulare Function und Hämodynamik bei intrakoronarer und intravenöser Gabe von Diltiazem. In: Bender F, Greef $\mathrm{K}$, eds. Calcium antagonisten zur Behandlung der Angina Pectoris, Hypertonie und Arrhythmie. Amsterdam-OxfordPrinceton: Excerpta Medica, 1982:87-93.

9. Leaman DM, Brower RW, Meester GT, Serruys PW, Brand $M$ van den. Coronary artery atherosclerosis: severity of the disease, severity of angina pectoris and compromised left ventricular function. Circulation 1981;63:285-92.

10. Baim DS, Rothman MT, Harrison DC. Improved catheter for regional coronary sinus flow and metabolic studies. $\mathrm{Am}$ J Cardiol 1980;46:997-1000.

11. Meester GT, Bernard N, Zeelenberg C, Brower RW, Hugenholtz PG. A computer system for real time analysis of cardiac catheterization data. Cathet Cardiovasc Diagn $1975 ; 1: 112-32$.

12. Meester GT, Zeelenberg C, Bernard N, Gorter S. Beat to beat analysis of cardiac catheterization data. In: Computers in cardiology Los Angeles: IEEE Computer Society, 1974:63-5.

13. Brower RW, Meij S, Serruys PW. A model of asynchronous left ventricular relaxation predicting the bi-exponential pressure decay. Cardiovasc Res 1983;17:482-8.

14. Slager CJ, Reiber JHC, Schuurbiers JCH, Meester GT. Contouromat - a hardwired left ventricular angio processing system. Design and application. Comput Biomed Res 1978;11:491-502.
15. Slager CJ, Hooghoudt TEH, Reiber JHC, Booman F Meester GT. Left ventricular contour segmentation from anatomical landmark trajectories and its application to wall motion analysis. In: Computers in cardiology. Los Angeles: IEEE Computer Society, 1980:374-50.

16. Hooghoudt TEH, Slager CJ, Reiber JHC, et al. "Regional contribution to global ejection fraction" used to assess the applicability of a new wall motion model to detection of regional wall motion in patients with asynergy. In: Computers in cardiology. Los Angeles: IEEE Computer Society, 1980:253-60.

17. Slager CJ, Hooghoudt TEH, Serruys PW, Reiber JHC, Schuurbiers JCH. Automated quantification of left ventricular angiograms. In: Short MD, ed. Physical techniques in cardiology imaging. Bristol: Hilger A, Ltd, 1982:163-72.

18. Chelly J, Cazor JL, Dandoy M, Garcia A, Carpentier A, Passelecq J. Hemodynamic and pharmacokinetic data of diltiazem infusions in patients after coronary surgery. Clin Pharmacol Ther 1982;31:210.

19. Zelis RF, Kinney EL. The pharmacokinetics of diltiazem in healthy american men. Am J Cardiol 1982;49:529-32.

20. Bache RJ, Dymek DJ. Effect of diltiazem on myocardial blood flow. Circulation 1982;65(suppl I):19-26.

21. Millard RW, Grupp G, Grupp IL, di Salvo J, de Pover A, Schwartz A. Chronotropic, inotropic and vasodilator actions of diltiazem, nifedipine and verapamil. Circ Res 1983;52:I29-39.

22. Nakaya H, Schwartz A, Millard RW. Reflex chronotropic and inotropic effects of calcium channel-blocking agents in conscious dogs. Circ Res 1983;52:302-11.

23. Mitchell LB, Jutzy KR, Lewis SJ, Schroeder JS, Mason JW. Intracardiac electrophysiologic study of intravenous diltiazem and combined diltiazem-digoxin in patients. Am Heart $J$ 1982;103:57-66.

24. Zipes DP, Besch HR, Watanabe AM. Role of the slow current in cardiac electrophysiology. Circulation 1974;51: 761-6.

25. Ellrodt G, Chew CYC, Singh BN. Therapeutic implications of slow channel blockade in cardiocirculatory disorders. Circulation 1980;62:669-79.

26. Zipes DP, Fischer JC. Effects of agents which inhibit the slow channel on sinus node automaticity and atrioventricular conduction in the dog. Circ Res 1974;34:184-92.

27. Kawai C, Konishi T, Matsuyama E, Okazaki H. Comparative effects of three calcium antagonists, diltiazem, verapamil and nifedipine, on the sinoatrial and atrioventricular nodes. Experimental and clinical studies. Circulation 1981;63:1035-49.

28. Padeletti L, Franchi F, Brat A, Dabizzi RP, Michelucci A. The cardiac electrophysiologic effects of nifedipine. Int $J$ Clin Pharmacol Biopharm 1979;17:290-3.

29. Rowland E, Evans T, Krikler D. Effect of nifedipine on atrioventricular conduction as compared with verapamil. Intracardiac electrophysiologic study. Br Heart $\vec{J}$ 1979;42: 124-7.

30. Rizzon P, DiBiase M, Calabrese P, Bridicci G, Chiddo A. Electrophysiologic evaluation of intravenous verapamil in man. Eur J Cardiol 1977;6:179-94.

31. Husaini MH, Kvasnicka J, Ryden L, Holmberg S. Action of verapamil on sinus node, atrioventricular and intraventricular conduction. Br Heart J 1973;35:734-7.

32. Henry PD. Comparative pharmacology of calcium antagonists: nifedipine, verapamil and diltiazem. Am J Cardiol 1980;46:1047-58.

33. Himori N, Ono H, Taira N. Simultaneous assessment of effects of coronary vasodilators on the coronary blood flow and the myocardial contractility by using the blood-perfused canine papillary muscle. Jpn J Pharmacol 1976;26:427-35.

34. Serruys PW, Wijns W, van den Brand M, et al. Left ventricular performance, regional blood flow, wall motion and lactate metabolism during transluminal angioplasty. Circulation 1984;70:25-36. 
35. Pouleur H, Rousseau MF, v Eyll C, Charlier AA. Assessment of regional left ventricular relaxation in patients with coronary artery disease: importance of geometric factors and change in wall thickness. Circulation 1984;69:696-702.

36. Weishaar R, Ashikawa K, Bing RJ. Effect of diltiazem, a calcium antagonist, on myocardial ischemia. Am J Cardiol 1979;43:1137-43.

37. Nagao M, Yasue H, Omote $S$, et al. Diltiazem-induced decrease of exercise-elevated pulmonary arterial diastolic pressure in hypertrophic cardiomyopathy in patients. $\mathrm{Am}$ Heart J 1981;102:789-90.

38. Fernandez F, Belfante M, Juillard A, et al. Effets du diltiazem sur les circulations cardiaque et coronair, au repos et au cours de la stimulation électrique auriculaire rapide. Arch Mal Coeur 1983;1:61-9.

39. Legrand V, Hastir F, Vandormael M, Collignon P, Kulbertus HE. Haemodynamic effects of intravenous diltiazem at rest and exercise in patients with coronary artery disease. Eur Heart $J$ 1984;5:456-63. 